\title{
FUTURE PROJECTION OF MEAN TEMPERATURE OF POST-MONSOON SEASON OVER BANGLADESH USING STATISTICAL DOWNSCALING OF GLOBAL CLIMATE MODELS
}

\author{
Md. Bazlur Rashid ${ }^{1 *}$ and Syed Shahadat Hossain ${ }^{2}$ \\ ${ }^{1}$ Bangladesh Meteorological Department, Agargaon, Dhaka-1207, Bangladesh \\ ${ }^{2}$ Institute of Statistical Research and Training (ISRT), University of Dhaka, Dhaka-1000, Bangladesh
}

Received: 2020

Accepted: 28 October 2020

\begin{abstract}
In statistical downscaling technique, regional or local information are derived by determining a statistical model which relates large-scale climate variables or predictors generated by Global Climate Models (GCMs) to regional and local variables or predictands. In this paper, the results of GCMs were statistically downscaled to produce future climate projections of mean temperature in the post-monsoon season (October and November), for the time periods 2021-2050 and 2071-2100 for Bangladesh. The future climate projections are based on the three emission scenarios RCP2.6, RCP4.5 and RCP8.5 provided by the fifth Coupled Model Intercomparison Project (CMIP5). This paper established a method to analyze GCMs for use in statistical downscaling and utilized fifteen GCMs. The GCMs were assessed based upon their performance in simulated past climate in Bangladesh and adjoining areas. Downscaling was undertaken by linking large scale climate variables, taken from the ERA-Interim (resolution $79 \mathrm{~km}$ ) reanalysis temperature, a gridded data set incorporating observations and climate models, to local scale observations. Overall, all fifteen GCMs, via statistical downscaling, show that mean temperature of the post-monsoon season in Bangladesh will increase under future climate scenarios. Comparing the ensemble of future projections with the reference period (19812010), the mean post-monsoon temperature in Bangladesh is projected for RCP8.5 showing warming by $0.31{ }^{\circ} \mathrm{C}$ in near future and $1.79^{\circ} \mathrm{C}$ in far future. On the other hand, estimated warming is $0.39^{\circ} \mathrm{C}$ in near future and $1.14^{\circ} \mathrm{C}$ is far future for RCP4.5. Low emission scenarios RCP2.6, near future temperature is nearly same the far future temperature.
\end{abstract}

Key words: Climate Change; Post-monsoon Season; Empirical Statistical Downscaling; GCM.

\section{INTRODUCTION}

Statistical downscaling is a technique that makes use of dependencies between large scale climate parameters and local surface variables. It involves calibrating a statistical model on historical observations which can then be used to generate future climate data by using in GCMs output for future climate scenarios, and is often carried out in order to conduct a climate change impact study on a regional scale (Wilby et al., 2004). The first statistical downscaling method was familiarized by Klein (1948), and a short description of the early history of statistical predictions was found in Klein and Bloom (1987). That time, downscaling was usually applied to numerical weather forecasting, and was then referred to as 'Specification'. In the initial 1980s (Kim et al., 1984), statistical downscaling was mentioned to as 'Statistical Problem of Climate Inversion'. However, a same technique, called 'Model Output Statistics' (MOS) has been used in numerical weather forecasting since the early 1970s (Baker, 1982). One reason why downscaling is a comparatively young science is that it depends on the presence of global climate models, which themselves denote recent advances in the climate science community.

The literature on statistical downscaling has concentrated on different countries, although there are some publications with a North American focus (Lapp et al., 2002; Benestad et al., 2015; 2016), as well as for Australia/New Zealand (Kidson and Thompson, 1998), Africa (Reason et al., 2006; Penlap et al., 2004), Asia (Oshima et al., 2002; Das and Lohar, 2005) and Bangladesh (Alamgir et al., 2019; Hasan et al., 2017; Nury et al., 2014; Rahaman, et al. 2015; Shourav et al., 2016). Rahaman et al. (2015) found that statistical downscaling model (SDSM) showed good agreement between observed and simulated maximum and minimum temperature so that it is able to predict future scenarios over Bangladesh with confidence. For precipitation, on the other hand, their results were not in such a good agreement. Statistical downscaling of modeled temperature and rainfall by GCM can easily be understood and adopted in order to minimize climate changes and its relevant impacts in Bangladesh (Nury et al., 2014). Hasan et al., (2017) found that the severity of summer-day temperatures would be alarming, especially over hilly regions, where winters would be relatively warm. Shourav et al. (2016) used SDSM to downscale future climate projections over the city of Dhaka, Bangladesh. Their study indicated that climate change would cause continuous increases of rainfall, temperature and weather-related extreme events. Karmakar (2019) found patterns of climate change and its impacts in 
northwestern Bangladesh and in the very recent, Paul et al. (2020) studied the past 100 years temperature data of Bangladesh and it found that in this period temperature of Bangladesh was risen by $1^{0} \mathrm{C}$ on average and an increment of close to another $1^{\circ} \mathrm{C}$ would be in the average temperature of Bangladesh from the prediction of the model in next century. Alamgir et al. (2019) analyzed that the greatest increase in maximum and minimum temperature was found in the more northern regions and the lowest increase was found in the southeast coastal regions. In the seasonal pattern, post-monsoon and winter would likely be warmer in the future than other seasons (Khan et al., 2020) and at same times during this post-monsoon, many devastative cyclones occurred in coastal regions of Bangladesh (Khatun et al., 2016). These studies, however, do not address the question of the changes in specific warming levels in post-monsoon season in Bangladesh.

The main objectives of the present study are to investigate the future projection of mean temperature of postmonsoon season in whole country as well as micro level in Bangladesh using 15 GCMs model and also find out temperature change based on three scenarios.

\section{DATA AND METHOD}

\subsection{Data description}

The analysis in this paper is based on mean temperature data from $15 \mathrm{GCM}$ simulations from the fifth phase of the Coupled Model Inter-comparison Project (CMIP5) ensemble (Table 1). The GCM data were downloaded from the KNMI Climate Explorer (https://climexp.knmi.nl/start.cgi) which offers data re-gridded to a 2.5degree resolution grid for the time period of 1900-2100. Three future scenarios (Representative Concentration Pathways, RCPs) were considered: the high emission scenario RCP8.5 (Riahi et al., 2007), the medium emission scenario RCP4.5 in which the radiative forcing stabilizes shortly after 2100 (Clarke et al., 2007), and the more optimistic peak-and-decline scenario RCP2.6 (Van Vuuren et al., 2007).

Local observations of the mean temperature from stations in Bangladesh were observed local variables data and are collected from the Bangladesh Meteorological Department (BMD). The ERA-Interim (resolution $79 \mathrm{~km}$ ) reanalysis data set is a global atmospheric reanalysis produced by the European Centre for Medium-Range Weather Forecasts (ECMWF). The ERA-Interim project was produced in part to prepare for a new atmospheric reanalysis to replace ERA-40.

Table 1: GCM simulations from the CMIP5 ensemble used in this paper. The rip index refers to the realization, initialization method and physics version

\begin{tabular}{llll}
\hline \multicolumn{1}{c}{ GCM } & \multicolumn{1}{c}{ rip } & \multicolumn{1}{c}{ GCM } & rip \\
\hline MPI-ESM-LR & r1i1p1 & GISS-E2-H & r5ilp \\
MPI-ESM-LR & r2i1p1 & GISS-E2-H-CC & r1i1p1 \\
MPI-ESM-LR & r3i1p1 & HadGEM2-ES & r1i1p1 \\
MPI-ESM-MR & r1i1p1 & HadGEM2-ES & r2i1p1 \\
MRI-CGCM3 & r1i1p1 & HadGEM2-ES & r3i1p1 \\
GISS-E2-H & r1i1p1 & HadGEM2-ES & r4i1p1 \\
GISS-E2-H & r1i1p2 & INMCM4.0 & r1i1p1 \\
\hline
\end{tabular}

\subsection{Data Analysis}

Statistical downscaling first generates statistical relationship between larger GCM scale variables and observed small-scale (station level) variables. Different approaches can be used such as analogue methods (rotation typing), regression analysis, or neural network techniques (Wilby et al., 2002). Future values of the large-scale variables found from GCM projections of future climate are then used to drive the statistical relationships in order to estimate the smaller-scale particulars of future climate.

Statistical models usually consist of equations as shown below.

$$
\begin{gathered}
\text { Small }- \text { scale }=f(\text { Geography }+ \text { Large }- \text { scale })+\text { Noise } \\
Y=f(g, X)+n
\end{gathered}
$$

Where $Y$ is the predictand (the small-scale climate), $g$ is the geography, $X$ is the predictor (a quantification of the large-scale patterns of the climate), and $\mathrm{n}$ is the noise term.

The empirical-statistical downscaling approach used in this study incorporated a form for quality control and bias adjustment through the practice of common Empirical Orthogonal Functions (EOFs) in the representation of the large-scale predictors (Benestad et al., 2015; 2016). After bias correction, a stepwise multiple regression was used to estimate model parameters, hence downscaling large scale climate variables to local scale. Such a 
statistical downscaling approach requires a smaller amount computational effort than dynamic downscaling and can be applied to many scenarios and longtime intervals, rather than the short-term slices of the dynamical downscaling method.

In this study Principal Component Analysis (PCA) was applied to the observational data before downscaling. The PCA decomposed the data into a set of spatial patterns, corresponding time series that describe the temporal variability associated with each pattern, and eigenvalues that represent the relative strength of each pattern. Rather than downscaling the observational stations individually, the time series associated with the first spatial patterns (hereby referred to as first principal components) were downscaled. The projected temperature could then be reconstructed from the downscaled principle components combined with the corresponding spatial patterns and eigenvalues.

\subsection{Analysis Software}

The study was carried out within the R-environment and used Empirical Statistical Downscaling (ESD) package (Benestad et al., 2015) to analyze the data for attaining the objectives. The development of the ESD software fits in with the trend of the R-language increasing role in the climate change debate and as an open science platform. Additionally, both R and the ESD R-package are appreciated tools for linking high education and research. The wide range of functionalities of the ESD tool, including methods for reading and manipulating data, generating various info-graphics, and performing statistical analysis (e.g., calculating EOF), PCA, canonical correlation analysis (CCA) and empirical-statistical downscaling creates it appropriate for processing results from GCMs.

\section{RESULTS AND DISCUSSIONS}

An analysis of the common EOFs of the GCM simulations and ERA-Interim reanalysis temperature was performed to assess the goodness of fit of the GCM output with respect to observation-based data. The residuals from the downscaled information were scrutinized against acceptability. Screening of predictors and predictor domains was conducted using GCM simulations, ERA-Interim reanalysis data, observed station data and the best correlated predictors and predictand were selected. Results of the statistical downscaling are shown in Figures 1, 2 and 3 for RCP2.6, RCP4.5 and RCP8.5 correspondingly.
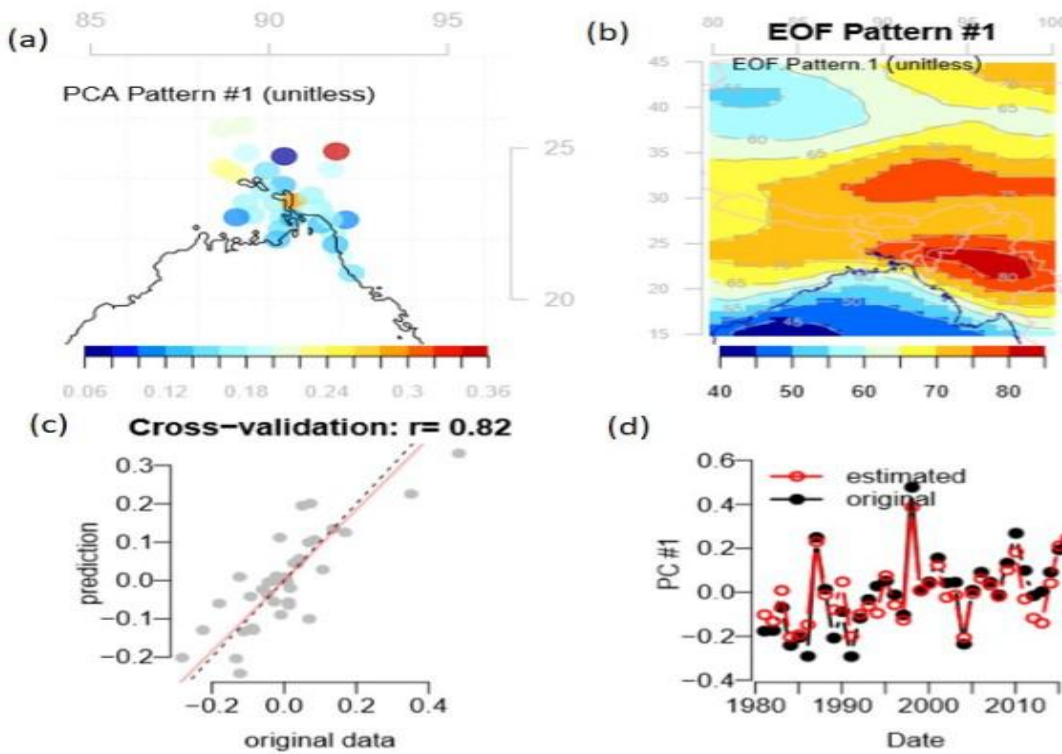

(d)

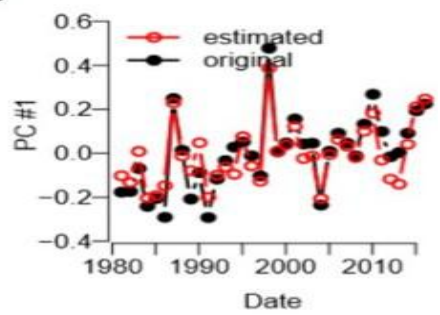

Figure 1: Downscaled mean temperature of the post monsoon season based on the ERA-Interim reanalysis and using PCA for downscaling a group of stations simultaneously for RCP2.6. Figure (a) shows the spatial pattern associated with the leading principle component (PC1) of the predictand, (b) captures the leading spatial pattern of the predictor, (c) shows a cross-validation comparing the original PC1 of the predictand and the corresponding estimated values obtained by empirical-statistical downscaling and figure (d) indicates time series of the estimated and original PC1 of the predictand.

The cross validated correlation between the PC1 of the mean temperature and the corresponding PC1 estimated based on empirical-statistical downscaling are $0.82,0.78$ and 0.8 for RCP2.6, RCP4.5 and RCP8.5 respectively. 
(a)

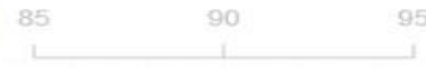

PCA Pattern \#1 (unitless)

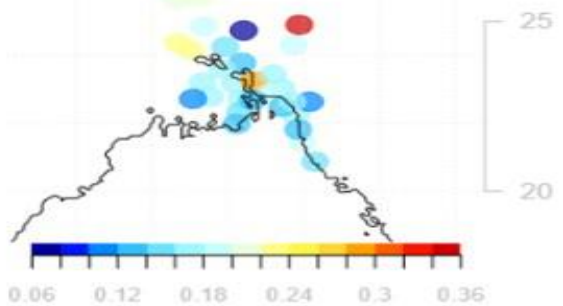

(c)

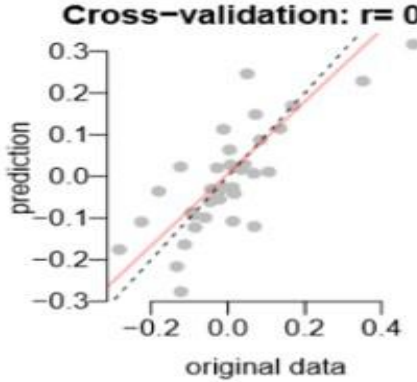

(b)

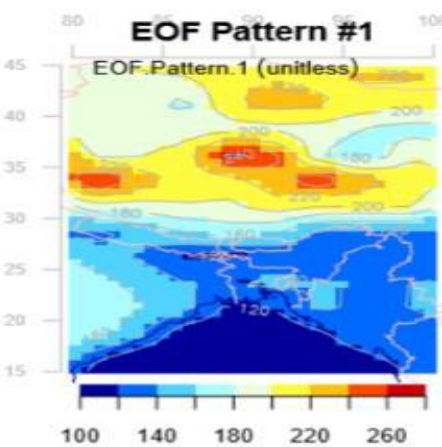

(d)

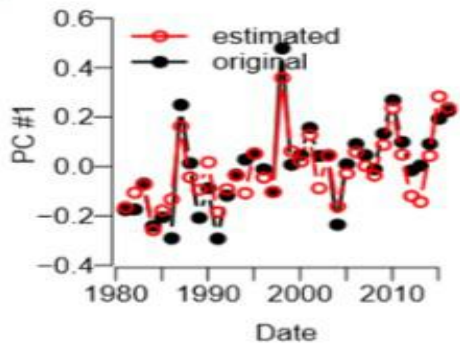

Figure 2: Downscaled mean temperature of the post monsoon season based on the ERA-Interim reanalysis and using PCA for downscaling a group of stations simultaneously for RCP4.5. Figure (a) shows the spatial pattern associated with the PC1 of the predictand, (b) captures the leading spatial pattern of the predictor, (c) shows a cross-validation comparing the original PC1 of the predictand and the corresponding estimated values obtained by empirical-statistical downscaling and figure (d) indicates time series of the estimated and original PC1 of the predictand.

(a)

PCA Pattern \#1 (unitless)

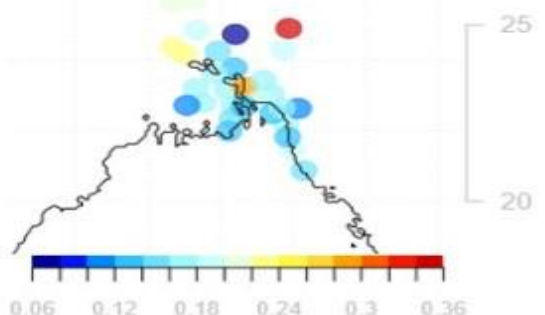

(c)

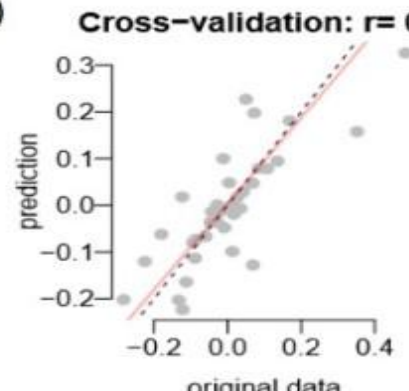

(b)

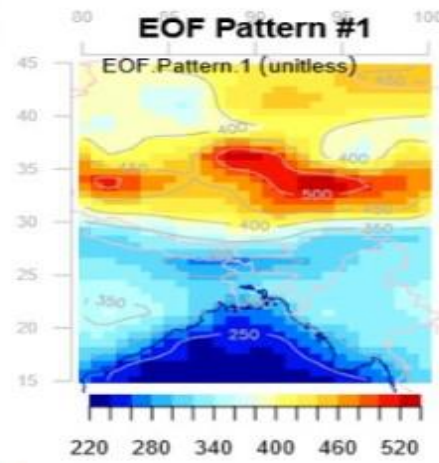

(d)

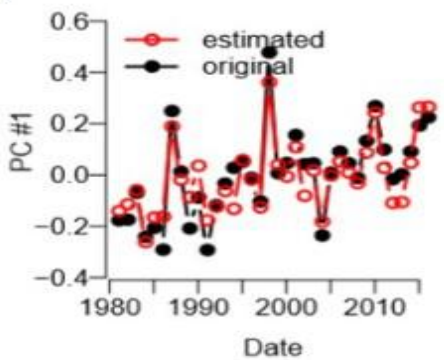

Figure 3: Downscaled mean temperature of the post monsoon season based on the ERA-Interim reanalysis and using PCA for downscaling a group of stations simultaneously for RCP8.5. Figure (a) shows the spatial pattern associated with the PC1 of the predictand, (b) captures the leading spatial pattern of the predictor, (c) shows a cross-validation comparing the original PC1 of the predictand and the corresponding estimated values obtained by empirical-statistical downscaling and figure (d) indicates time series of the estimated and original PC1 of the predictand. 

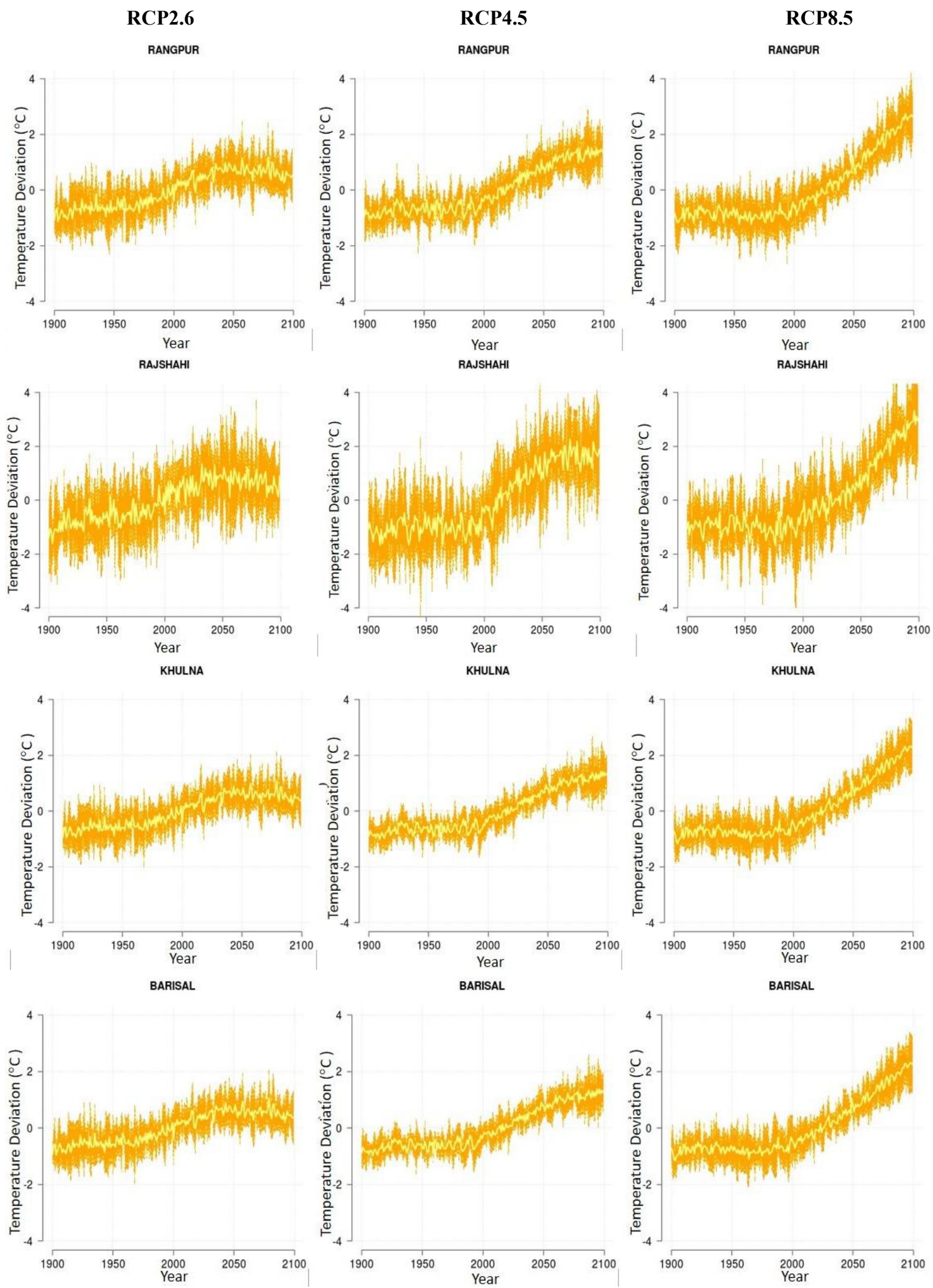

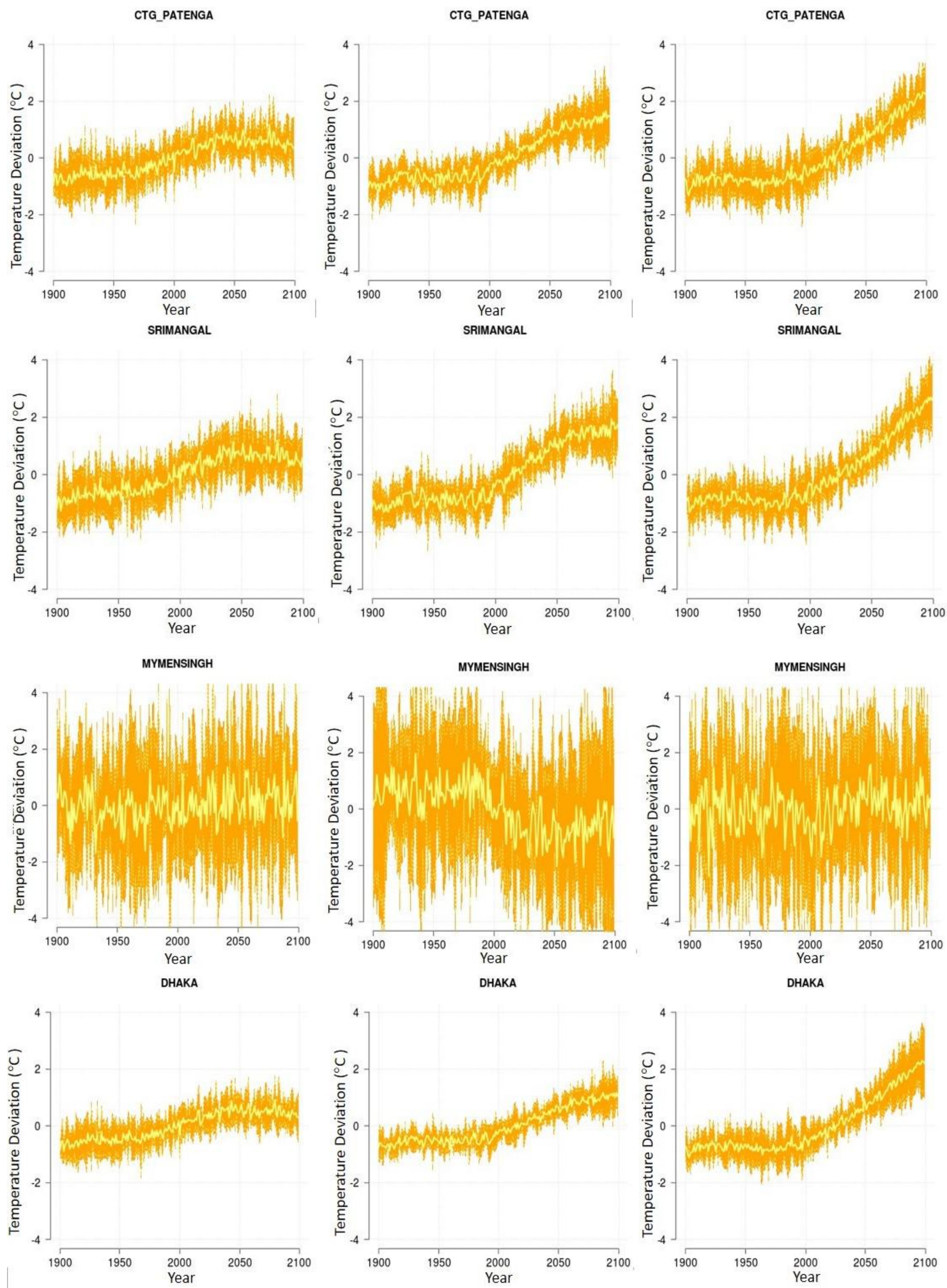

Figure 4: Mean temperature of post monsoon season over regional points change for different RCP scenarios run by CMIP5 experiments, respectively, relative to the period 1981-2010. The shaded area shows one standard deviation from the mean based on all scenarios for each experiment

Figures 4 showed downscaled climate projections for different RCPs (RCP2.6, RCP4.5 and RCP8.5). The results are summarized in Table 2, which includes the average change in the mean temperature of the postmonsoon season relative to 1981-2010 for two periods: the near future (2021-2050) and the far future (2071- 
2100). The downscaled projections indicated an increase in the post-monsoon temperature at Dhaka by $0.49^{\circ} \mathrm{C}$ for near future and $0.48^{\circ} \mathrm{C}$ for far future with RCP2.6, but for RCP4.5 the near future warming was estimated to be $0.35^{\circ} \mathrm{C}$ and far future was same $0.99^{\circ} \mathrm{C}$. The scenario, RCP8.5, suggested increases of post-monsoon temperature by $0.28^{\circ} \mathrm{C}$ and $1.85^{\circ} \mathrm{C}$ for the near and far future, respectively.

The mean projected change in post-monsoon temperature for Bangladesh assuming $\mathrm{RCP} 4.5$ was $0.39^{\circ} \mathrm{C}$ for the near future and $1.14^{\circ} \mathrm{C}$ for the far future. For the high emission scenario RCP8.5, the near future estimated warming was near future $0.31^{\circ} \mathrm{C}$ but the far future warming was considerably higher $1.79^{\circ} \mathrm{C}$. The highest projected warming for $\mathrm{RCP} 2.6$ was $0.94^{\circ} \mathrm{C}$ at Chandpur for the near future and $0.91^{\circ} \mathrm{C}$ at same place for the fur future and for RCP4.5 captured $0.85^{\circ} \mathrm{C}$ at Rajshahi for the near future and $2.05^{\circ} \mathrm{C}$ at Chandpur for the far future. For the most severe emission scenario, RCP8.5, the projected warming was $0.53^{\circ} \mathrm{C}$ at Chandpur for the near future and $2.82^{\circ} \mathrm{C}$ at same place for the far future.

The emission scenario RCP2.6 assumes very low future emissions. In a broad sense, $\mathrm{CO}_{2}$ emissions will remain constant until early this century and will become negative by the end of the century. This scenario assumes a sharp decline in the use of cropland for biofuel production, and reduction of methane emissions by $40 \%$. Based on these conditions, models nicely captured the mean temperature of the post-monsoon season and indicate lower temperature for the far future over Bangladesh with an exception only two places such as Tangail and Mymensingh regions where it indicates higher temperature increment during far future period.

Table 2: Mean anomaly mean temperature in post-monsoon season based on 1981-2010

\begin{tabular}{|c|c|c|c|c|c|c|c|}
\hline \multirow[t]{3}{*}{ Division } & \multirow{3}{*}{$\begin{array}{c}\text { Station } \\
\text { Location }\end{array}$} & \multicolumn{6}{|c|}{ Emission scenario } \\
\hline & & \multicolumn{2}{|c|}{ RCP2.6 } & \multicolumn{2}{|c|}{ RCP4.5 } & \multicolumn{2}{|c|}{ RCP8.5 } \\
\hline & & $\begin{array}{c}\text { Near } \\
\text { Future }\end{array}$ & $\begin{array}{c}\text { Far } \\
\text { Future }\end{array}$ & $\begin{array}{c}\text { Near } \\
\text { Future }\end{array}$ & $\begin{array}{c}\text { Far } \\
\text { Future }\end{array}$ & $\begin{array}{c}\text { Near } \\
\text { Future }\end{array}$ & $\begin{array}{c}\text { Far } \\
\text { Future }\end{array}$ \\
\hline \multirow[t]{3}{*}{ Dhaka } & Dhaka & 0.49 & 0.48 & 0.35 & 0.99 & 0.28 & 1.85 \\
\hline & Tangail & 0.48 & 0.49 & 0.20 & 0.83 & 0.30 & 1.51 \\
\hline & Faridpur & 0.60 & 0.59 & 0.39 & 1.13 & 0.33 & 2.24 \\
\hline Mymensingh & Mymensingh & 0.15 & 0.24 & -0.73 & -0.57 & 0.35 & 0.10 \\
\hline \multirow[t]{11}{*}{ Chattogram } & Chattogram & 0.59 & 0.56 & 0.46 & 1.33 & 0.35 & 1.86 \\
\hline & Cox Bazar & 0.67 & 0.64 & 0.55 & 1.53 & 0.37 & 2.11 \\
\hline & Chandpur & 0.94 & 0.91 & 0.69 & 2.05 & 0.53 & 2.82 \\
\hline & Cumilla & 0.58 & 0.57 & 0.40 & 1.17 & 0.32 & 2.03 \\
\hline & Feni & 0.58 & 0.57 & 0.41 & 1.22 & 0.34 & 1.94 \\
\hline & Kutubdia & 0.66 & 0.62 & 0.62 & 1.57 & 0.33 & 2.11 \\
\hline & M.Court & 0.32 & 0.32 & 0.14 & 0.60 & 0.21 & 0.86 \\
\hline & Rangamati & 0.41 & 0.40 & 0.22 & 0.83 & 0.27 & 1.20 \\
\hline & Sandwip & 0.15 & 0.24 & -0.73 & -0.57 & 0.35 & 0.10 \\
\hline & Sitakunda & 0.60 & 0.58 & 0.44 & 1.28 & 0.35 & 2.02 \\
\hline & Teknaf & 0.56 & 0.50 & 0.62 & 1.74 & 0.39 & 1.25 \\
\hline \multirow[t]{3}{*}{ Khulna } & Khulna & 0.57 & 0.55 & 0.43 & 1.21 & 0.30 & 1.89 \\
\hline & Jashore & 0.54 & 0.53 & 0.39 & 1.09 & 0.29 & 1.88 \\
\hline & Satkhira & 0.40 & 0.39 & 0.33 & 0.85 & 0.21 & 1.51 \\
\hline \multirow[t]{4}{*}{ Barishal } & Barishal & 0.55 & 0.53 & 0.42 & 1.17 & 0.30 & 1.87 \\
\hline & Patuakhali & 0.45 & 0.44 & 0.31 & 0.94 & 0.25 & 1.43 \\
\hline & Bhola & 0.46 & 0.45 & 0.33 & 0.97 & 0.27 & 1.58 \\
\hline & Khepupara & 0.46 & 0.45 & 0.36 & 1.01 & 0.25 & 1.50 \\
\hline \multirow[t]{2}{*}{ Rajshahi } & Rajshahi & 0.70 & 0.65 & 0.85 & 1.67 & 0.17 & 2.52 \\
\hline & Bogura & 0.64 & 0.63 & 0.47 & 1.30 & 0.33 & 2.20 \\
\hline \multirow[t]{2}{*}{ Rangpur } & Rangpur & 0.64 & 0.62 & 0.50 & 1.30 & 0.30 & 2.20 \\
\hline & Dinajpur & 0.65 & 0.64 & 0.44 & 1.26 & 0.34 & 2.24 \\
\hline \multirow[t]{2}{*}{ Sylhet } & Srimangal & 0.65 & 0.61 & 0.65 & 1.55 & 0.29 & 2.18 \\
\hline & ntry & 0.55 & 0.53 & 0.39 & 1.14 & 0.31 & 1.79 \\
\hline
\end{tabular}

RCP4.5 describes a scenario of low to moderate future emissions. As per this scenario, $\mathrm{CO}_{2}$ emissions will be increased slightly until the mid-century and declined afterwards. The use of energy will decline sharply and there will be large-scale reforestation. In this situation new climate policies will be introduced and methane emissions will be stabilized. Table 2 indicates that the post-monsoon mean temperature values in the near future for RCP4.5 will be lowered than that for RCP2.6 and higher than that for RCP8.5. On the other hand, warming condition far future will be higher for RCP4.5 than that for RCP2.6 but lower than that for RCP8.5. 
RCP8.5 explains a scenario of very high future emissions by the end of this century and $\mathrm{CO}_{2}$ emissions will be expected three times higher than the present status. There will also be a large increase in methane emission. Energy use will be further increased and that will be covered mostly by using fossil fuels. As a result, temperatures will be increased considerably in the far future. From Table 2 it is seen that the magnitudes of the projected temperature for the far future for RCP8.5 will always be higher than the corresponding values based on emission scenarios for RCP2.6 and RCP4.5.

\section{CONCLUSIONS}

From this study the following results can be drawn:

i. This statistical downscaling is a suitable technique for downscaling the mean temperature to local scale of post-monsoon season in Bangladesh. Though GCM data are provided with a coarse resolution, but ESD technique can capture the local response to large scale climate change variability;

ii. The cross validated correlation between the PC1 of mean temperature of Bangladesh and the corresponding PC1 estimated based on ERA-Interim data are caught very high;

iii. Compared to the reference period of 1981-2010, the projected mean temperature in post-monsoon at country level for RCP2.6, the estimated mean temperatures are nearly same at near and far future overall Bangladesh;

iv. Based on assumptions RCP2.6, models captured very well that the mean temperature of post-monsoon season was lower for the far future than for the near future over different locations in Bangladesh, with the exception of Tangail \& Mymensingh;

v. Results from this study indicate that the mean temperature of post-monsoon season differences of the near future and fur future for RCP4.5 are slight rise at fur future. So, if we would follow strict new climate polices among mid this century, fur future post-monsoon temperature of Bangladesh will be increased almost $0.39^{\circ} \mathrm{C}$ in the near future and $1.14^{\circ} \mathrm{C}$ in the far future;

vi. As a result of conditions RCP8.5, we shall not follow any climate related polices, mean temperature of post-monsoon season will increase considerably in the far future. From this study, it is seen that projected values of temperature for RCP8.5 will increase by $0.31{ }^{\circ} \mathrm{C}$ in the near future and $1.79^{\circ} \mathrm{C}$ in the far future overall Bangladesh.

\section{ACKNOWLEDGEMENTS}

Authors are grateful to Mr. Rasmus E. Benestand, Abdul Kader Mezghani \& Kajsa M. Parding who are developer of ESD packages and for their great supporting to run it. Special thanks Mr. Hans Olav Hygen, Norwegian Meteorological Institute due to teach me ' $\mathrm{R}$ ' language which has enriched in this paper. Authors are extremely thankful to BMD for providing necessary climate data.

\section{REFERENCES}

Alamgir, M., Ahmed K., Homsi, R., Dewan A., Wang J. J. and Shahid S., 2019. Downscaling and Projection of Spatiotemporal Changes in Temperature of Bangladesh, Earth Syst. Environ., 3, 381-398. DOI: https://doi.org/10.1007/s41748-019-00121-0

Baker, D. G., 1982. Synoptic-Scale and Mesoscale Contributions to Objective Operational Maximum-Minimum Temperature Forecast Errors, Monthly Weather Review, 110, 163-169.

Benestad, R., and Mezghani A., 2015. On downscaling probabilities for heavy 24-hr precipitation events at seasonal-to-decadal scales, Tellus A., 67, 25954. DOI: http://dx.doi.org/10.3402/tellusa.v67. 25954.

Benestad, R. E., Parding K.M., Isaksen K., and Mezghani A., 2016. Climate change and projections for the Barents region: what is expected to change and what will stay the same? Environ. Res. Lett., 11 054017.

Clarke, L.E., Edmonds J.A., Jacoby H.D., Pitcher H., Reilly J. M., and Richels R., 2007. Scenarios of greenhouse gas emissions and atmospheric concentrations. Sub-report 2.1a of Synthesis and Assessment Product 2.1. Climate Change Science Program and the Subcommittee on Global Change Research, Washington DC.

Das, L., and Lohar D., 2005. Construction of climate change scenarios for a tropical monsoon region, Climate Research, 30, 39-52.

Hasan, M.A., Islam A.S., and Akanda A.S., 2017. Climate Projections and Extremes in Dynamically Dowscaled CMIP5 Model Outputs over the Bengal Delta: A quartile Based Boas-correction Approach with New Girdded Data, Climate Dynamics, DIO: https://doi.org/10.1007/s00382-017-4006-1

Karmakar, S., 2019: Patterns of Climate Change and Its Impacts in Northwestern Bangladesh, Journal of Engineering Science, 10(2), 33-48. 
Khan, M.J.U., Islam A.K.M.S., Bala S.K. et al, 2020. Changes in climate extremes over Bangladesh at $1.5^{\circ}$ C, $2^{\circ} \mathrm{C}$ and $4^{0} \mathrm{C}$ of global warming with high-resolution regional climate modeling, Theor Apl Climatol, 140, 1451-1466, DIO: https://doi.org/10.1007/s00704-020-03164-w.

Khatun, M.A., Rashid M.B., and Hygen H.O., 2016. Climate of Bangladesh, Met report, no 08, ISSN23874201, Climate.

Kim, J.-W., Chang J.-T., Baker N.L., Wilks D.S., and Gates W.L., 1984. The Statistical Problem of Climate Inversion: Determination of the Relationship between Local and Large-Scale Climate, Monthly Weather Review, 112, 2069-2077.

Kidson, J.W., and Thompson C.S., 1998. A Comparison of Statistical and Model-Based Downscaling Techniques for Estimating Local Climate Variations. Journal of Climate, 11, 735-753.

Klein, W.H., 1948. Winter precipitation as related to the 700-millibar circulation, Bull. Amer. Meteor. Soc., 9, $439-4.53$.

Klein, W.H., and Bloom H.J., 1987. Specification of Monthly Precipitation over the United States from the Surrounding $700 \mathrm{mb}$ Height Field, Mon.Wea. Rev., 115, 2118-2132.

Lapp, S., Byrne J., Kienzle S., and Townshend I., 2002. Linking global circulation model synoptic and precipitation for western North America, International Journal of Climatology, 22, 1807-1817.

Nury A. H., and Alam M.J.B., 2014. Performance Study of Global Circulation Model HADCM3 Using SDSM for Temperature and Rainfall in North-Eastern Bangladesh, Sci. Res. 6 (1), 87-96.

Oshima, N., Kato H., and Kadokura S., 2002. An application of statistical downscaling to estimate surface air temperature in Japan, Journal of Geophysical Research, 107(D10), ACL-14.

Paul, S., and Roy S., 2020. Forecasting the Average Temperature Rise in Bangladesh: A Time Series Analysis, Journal of Engineering Science, 11(1), 83-91

Penlap, E.K., Matulla M., von Storch H., and Kamga F.M., 2004. Down-scaling of GCM scenarios to assess precipitation changes in the little rainy season (March-June) in Cameroon, Climate Research, 2.6, 8.596.

Rahaman, A. Z., Khan F.A., Aktar N., and Noor F., 2015. Climate Change Scenarios of Bangladesh using Statistical downscaling Model, $5^{\text {th }}$ International Conference on Water \& Flood Management (ICWFM -2015).

Reason, C. J. C., Landman W., and Tennantc W., 2006. Seasonal to Decadal Prediction of Southern African Climate and Its Links with Variability of the Atlantic Ocean. Bull. Amer. Meteor. Soc., 87, 182-190.

Riahi, K., Grübler A., and Nakicenovic N., 2007. Scenarios of long-term socio-economic and environmental development under climate stabilization, Technol Forecast Soc. Chang., 74, 887-935.

Shourav, M.S.A., Mohsenipour M., Alamgir M., Hadipour S., and Ismail T., 2016. Historical trends and future projection of climate at Dhaka city of Bangladesh, Journal Teknologi (Sciences \& Engineering) 78, 6$12,69-75$.

Van Vuuren, D.P., Den Elzen M.G.J., Lucas P.L., Eickhout B., Strengers B.J., Van Ruijven B., Wonink S., and Van Houdt R., 2007. Stabilizing greenhouse gas concentrations at low levels: an assessment of reduction strategies and costs, Clim Change, 81, 119-159.

Wilby, R.L., Dawson C.W., Barrow E.M., 2002. SDSM a Decision Support Tool for the Assessment of Regional Climate Change Impacts, Environmental Modeling Software, 17, 147-159.

Wilby, R. L., Charles S. P., Zorita E., Timbal B., Whetton P., and Mearns L. O., 2004. Guidelines for Use of Climate Scenarios Developed from Statistical Downscaling Methods, IPCC Task Group on Data and Scenario Support for Impacts and Climate Analysis (TGICA), 27pp.

(C) 2020 The Authors. Journal of Engineering Science published by Faculty of Civil Engineering, Khulna University of Engineering \& Technology. This is an open access article under the terms of the Creative Commons Attribution-NonCommercial-NoDerivatives License, which permits use and distribution in any medium, provided the original work is properly cited, the use is non-commercial and no modifications or adaptations are made. 